\title{
Punicic acid: A striking health substance to combat metabolic syndromes in humans
}

\author{
Muhmmad Asim Shabbir, Moazzam Rafiq Khan, Muhammad Saeed, Imran Pasha, Anees Ahmed Khalil \\ and Naila Siraj
}

\begin{abstract}
Punicic acid, a bioactive compound of pomegranate seed oil has gained wide attention for their therapeutic potential. Different studies conducted on animal and human models have revealed that punicic acid is very effective against various chronic diseases. Substantial laboratory works has been carried out to elaborate punicic acid effectiveness and mechanism of action in animals. The intention of this review article is to explore the facts about the clinical trials of punicic acid and to discuss different future strategies that can be employed to use it in human clinical trials. Although punicic acid may represent a novel therapeutic unconventional approach for some disorders, still further experimental studies are required to demonstrate its effects in human beings.
\end{abstract}

Keywords: Punicic acid, Conjugated linoleic acid, Conjugated linolenic acid, Fatty acids, Antioxidant

\section{Background}

Fruits and vegetables transformation into valuable products produces a huge amount of by-products that are considered to have a lot of bio-active compounds [1]. Pomegranate transformed to various edible products mainly fresh seeds, juice, nectars, jams and jellies. During the processing of pomegranate a large quantity of pomegranate waste is produced which has lots of nutritional components but mostly this waste is dumped off that creates environmental pollution and is also the wastage of nutritional components. In last few years, a huge excerpt of research work is conducted on the industrial by-products of pomegranate and found that these by-products have antioxidant, anti glycemic potential and antimicrobial activity. The multifarious reported functional attributes of pomegranate make it a unique fruit from other fruits. Due to the higher antioxidant potential of pomegranate fruit and its other parts e.g. juice, seed, peel etc., it has been reported that this fruit has advantageous health benefits for human body. This encouraged the nutritionists and scientists to find out more potential and beneficial bioactive ingredients for nutraceutical and food industry applications [2].

* Correspondence: nailaateeq02@gmail.com

National Institute of Food Science and Technology, University of Agriculture, Faisalabad 38000, Pakistan
Pomegranate processing produces bagasse as a byproduct after juice extraction that can be used as a valuable ingredients in other edible products but still its application is scarce. However, the research conducted in past revealed that the pomegranate seed residues (PSRs) have the potential to use in food products for different intentions. PSRs composed of sterols, polyphenols, tocopherols and octadecatrienoic acid (punicic acid). PSRs are the richest source of rare and unique pomegranate seed oil (PSO), an exotic, fruity aroma oil and used in aromatherapy with healing and the antioxidant potential for skin and breast cancer as concluded from different studies. PSO extracted by various extraction methods including organic solvent extraction, supercritical $\mathrm{CO}_{2}\left(\mathrm{SC}-\mathrm{CO}_{2}\right)$ extraction and cold press extraction. Cold press extracted PSO has better physiochemical and nutritious quality as compared to other extraction methods $[3,4]$ with no impacts on environment. In $\mathrm{SC}-\mathrm{CO}_{2}$ extraction method, the extraction pressure is the cardinal factor to reduce the PSO production [5]. PSO possessed the elevated level of punicic acid (PA) and tocopherol contents that decreased slightly with increase in temperature and pressure. However, an effective intelligent system was developed to investigate the effect of temperature and pressure during $\mathrm{SC}-\mathrm{CO}_{2}$ on PSO yield and described that properly developed radial basis function and back-propagation neural 
network could be useful in predicting the effect of temperature and pressure on PSO yield in $\mathrm{SC}-\mathrm{CO}_{2}$ extraction process [6]. PSO extracted through hexane by soxhlet method has superior quality as compared to subcritical propane and $\mathrm{SC}-\mathrm{CO}_{2}$ extracted oil. Subcritical propane and $\mathrm{SC}-\mathrm{CO}_{2}$ extraction method showed the efficiency up to $77 \%$ and $59 \%$ of total PSO as compared to extracted by soxhlet method [7].

PSO extracted through ultrasonic-assisted extraction method with optimized condition for best yield at solidliquid ratio of $1: 12 \mathrm{~g} / \mathrm{mL}$ with extraction temperature $51^{\circ} \mathrm{C}$ at $70 \mathrm{~W}$ for 40 minutes and $19 \%$ PSO yield with major fatty acids PA (65\%), linoleic acid (10\%) and oleic acid (9\%) [8]. PSO showed the extraction efficiency in various solvents as followed: petroleum ether $>$ n-hexane $>$ ethyl acetate $>$ ether $>$ acetone $>$ isopropanol [9]. Some other parameters such as ultrasonic power, time for extraction, solids: solvent ratio, and temperature were optimized with petroleum ether by surface response methodology. PSO extracted through ultrasonic assisted extraction showed superior quality and higher yield as compared to supercritical and soxhlet extraction methods. The effect of different extraction methods on the total phenolic contents extracted from pomegranate seeds of the Malas variety from Iran was studied and reported that different experimental conditions with supercritical extraction method can affect the phenolic contents. The temperature, pressure, and volume of modifier inversely proportional to phenolic extraction [10].

\section{Punicic acid (PA)}

Various researchers have reported pomegranate as a functional fruit owing to presence of wide range of phytochemicals in it [11]. Purposely, antioxidative properties of juice, peel and seed have been examined for their therapeutic potential, which has prompted the nutritionists to further explore their nutraceutical and industrial application [2]. Its underutilized seed and peel portion, normally known as agro-waste obtained during industrial processing of pomegranate juice, are gaining attention of researchers now a days due to presence of array of nutraceutics in them. Abundant presence of pomegranate seed is of keen interest to scientist because of rich composition of oil [12]. Pomegranate seed oil possesses rich polyunsaturated fatty acid composition, predominantly comprising of punicic acid $(\sim 55 \%)$ as characterized by Melo [13]. This review summarizes PA and its role as a nutraceutical health substance.

PA is also recognize as "Trichosanic acid" with molecular formula $\mathrm{C}_{18} \mathrm{H}_{30} \mathrm{O}_{2}$ while its molar mass is 278.43 $\mathrm{g} / \mathrm{mol}$ with melting point of $44-45^{\circ} \mathrm{C}$. Punicic acid is an isomer of conjugated $\alpha$-linolenic acid and a $\omega-5$ polyunsaturated fatty acid which have structural resemblance with conjugated $\alpha$-linolenic and linoleic acid, for instance number of double bonds and atomic arrangement. Due to health benefits associated with these fatty acids, scientists are showing great interest in exploring functional and nutraceutical properties of punicic acid against various metabolic ailments [14, 15].

The International Union of Pure and Applied Chemistry (IUPAC) designated its names as 9Z, 11E, 13Z-octadeca-9, 11, 13-trienoic acid on the basis of its three double bonds (cis9, trans11 and cis13). Principally, it is an isomer of conjugated linoleic acid (c9t11) having a double bond on its tail side. Other isomers of lenolic acid are catalpic acid (trans9, trans11, cis13), alpha-eleostearic acid (cis9, trans11, trans13), calendic acid (trans8, trans 10, cis 12$)$ and jacaric acid (cis8, trans10, cis12). PA is named after its principle source pomegranate (Punica granatum L.). Among all the sources of PA it is most abundantly present in pomegranate seed oil (PSO). The other sources for PA are snake gourd seed oil [16] and Trichosanthes kirilowii Maxim (TK) seeds (Table 1) containing 32 to $40 \%$ PA out of total seed weight [50: 9: 32]. Whereas, fatty acid profile of PSO contains conjugated linoleic acid up to $74-85 \%$ PA [17] and remaining $14-25 \%$ are its isomers [18]. PA could be chemically synthesized by dehydration and isomerization of secondary oxidation products of linoleic and alpha-linolenic acids $[19,20]$. Primarily, PA is reported to be effective against ailments like obesity, diabetics, inflammation, metabolic syndromes in various in vivo experiments (Table 2) that's why pomegranate seed lipid portion (principal by-product) was studied after juice extraction as lipolytic enzymes deactivate during thermal processing [21].

\section{Metabolism of punicic acid}

Numerous pharmacokinetics studies have been carried out on animals to assess the metabolism and bioavailability of PA. Results of efficacy trials revealed substantial evidence that PA is readily metabolized to circulating conjugated linoleic acid (c9t11) as depicted in Fig. 1 [22, 23]. Similarly,

Table 1 Sources of punicic acid

\begin{tabular}{lll}
\hline Sources of punicic acid (PA) & & Authors \\
\hline Pomegranate (Seed oil) & $10 \%$ & \\
$\quad$ Saturated & $10 \%$ & \\
Mono-unsaturated & $10 \%$ & \\
Di-unsaturated & $70 \%$ & \\
$\quad$ Punicic acid and isomer (C18: 3-9c,11t,13c) & & [53] \\
Trichosanthes kirilowii (seed oil) & $7.50 \%$ & \\
$\quad$ Saturated & $22.91 \%$ & \\
$\quad$ Mono-unsaturated & $32.70 \%$ & \\
$\quad$ Di-unsaturated & $35.89 \%$ & \\
Punicic acid and isomer (C18: 3-9c,11t,13c) & & \\
\hline
\end{tabular}


Table 2 Summary of health effects of punicic acid (PA) on animal and human model

\begin{tabular}{|c|c|c|c|c|}
\hline Level of PA & $\begin{array}{l}\text { Study model } \\
\text { system }\end{array}$ & Mechanism of activity & Outcomes & Authors \\
\hline $5 \%$ punicic acid & ICR CD-1 mice & $\uparrow \mathrm{CPTI}$ activity & $\begin{array}{l}\text { Decreased perirenal } \\
\text { and epididymal fat }\end{array}$ & [46] \\
\hline $\begin{array}{l}5 \% \text { pomegranate seed } \\
\text { (punicic acid) }\end{array}$ & OLEFT rats & $\downarrow \Delta 9$ desaturase activity & $\begin{array}{l}\text { Adipose tissues weight } \\
\text { reduction }\end{array}$ & [44] \\
\hline $1 \%$ punicic acid & C57BI/J6 mice & - & $\begin{array}{l}\text { Adipose tissues weight } \\
\text { reduction }\end{array}$ & [17] \\
\hline $\begin{array}{l}\text { 10-100 } \mu \mathrm{M} \text { mixture of CLnA isomers (cis-9,trans- } \\
11, \text { cis-15, and cis-9,trans-13,cis-15) }\end{array}$ & 3T3-L1 cells & $\uparrow \mathrm{HSL}$ and ATGL gene expression & Decreased triglyceride content & [75] \\
\hline $\begin{array}{l}10 \text { and } 50 \mu \mathrm{g} / \mathrm{mL} \\
\text { pomegranate seed } \\
\text { (punicic acid) }\end{array}$ & 3T3-L1 cells & $\downarrow P P A R_{\gamma}$ and $C^{-E B P} P_{\beta} \downarrow$ FAS & $\begin{array}{l}\text { Decreased adipogenesis and } \\
\text { preadipocyte differentiation }\end{array}$ & [56] \\
\hline Punicic acid & C57Bl/J6 mice & - & $\begin{array}{l}\text { Insulin sensitivity enhanced in } \\
\text { peripheral area }\end{array}$ & [46] \\
\hline Punicic acid & $\begin{array}{l}\text { 3T3-L1 cells and } \\
\text { obese mice }\end{array}$ & PPARa and PPAR $\beta$ activation & $\begin{array}{l}\text { Improved glucose tolerance, } \\
\text { with diabetes improvement }\end{array}$ & [76] \\
\hline Punicic acid & HepG2 cells & $\begin{array}{l}\downarrow \text { apoB100 secretion. Inhibition } \\
\text { of stearoyl CoA desaturase }\end{array}$ & $\begin{array}{l}\downarrow \text { Plasma triacylglycerides. } \\
\text { Upgraded saturated/ } \\
\text { monounsaturated fatty } \\
\text { acid ratio }\end{array}$ & [47] \\
\hline $\begin{array}{l}\text { Catalpic acid, jacaric acid, } \\
\text { calendic acid, eleostearic } \\
\text { acid and punicic acid, }\end{array}$ & $\begin{array}{l}\text { Microsomes } \\
\text { from sheep } \\
\text { vesicular glands }\end{array}$ & $\begin{array}{l}\text { Inhibition of cyclooxygenase activity } \\
\text { (inhibition of prostaglandin synthesis) }\end{array}$ & Anti-inflammatory activity & [77] \\
\hline Punicic acid & Sheep & $\begin{array}{l}\text { Inhibit cyclooxygenase and } \\
\text { lipoxygenase activity }\end{array}$ & Anti-inflammatory activity & [78] \\
\hline $\begin{array}{l}\text { Pomegranate extract } \\
\text { (punicic acid) }\end{array}$ & 3T3-L1 cells & $\begin{array}{l}\text { PPARY receptor activator and } \\
\text { agonist (inhibit NF-k } \beta \text { expression, } \\
\text { declined serum IL-6 and TNF-a) }\end{array}$ & Decreased chronic inflammation & [76] \\
\hline $\begin{array}{l}\text { Alpha-Eleostearic and } \\
\text { punicic acid }\end{array}$ & Diabetic rats & $\begin{array}{l}\text { Inhibit NF-k } \beta \text { expression. Declined } \\
\text { serum IL-6 and TNF-a. }\end{array}$ & Anti-inflammatory activity & [37] \\
\hline $\begin{array}{l}\text { Punicic acid ( } 70 \% \\
\text { pomegranate seed oil) }\end{array}$ & - & $\begin{array}{l}\text { Decreased expression PPARy and } \\
\text { C/EBPs, and fatty acid synthase }\end{array}$ & $\begin{array}{l}\text { Suppresses adipocyte } \\
\text { differentiation and lipid } \\
\text { accumulation }\end{array}$ & [56] \\
\hline Punicic acid & $\begin{array}{l}\text { Ovariectomized } \\
(O V X) \text { mice }\end{array}$ & $\begin{array}{l}\text { Down-regulate the expression of } \\
\text { osteoclast differentiation markers } \\
\text { and RANK-RANKL downstream } \\
\text { signaling targets in osteoclast-like } \\
\text { cells (RAW264.7) }\end{array}$ & $\begin{array}{l}\text { Improved bone mineral density } \\
\text { and prevented trabecular micro- } \\
\text { architecture impairment }\end{array}$ & [63] \\
\hline $\begin{array}{l}\text { Dietary mono-conjugated } \\
\text { alpha-linolenic acid isomers }\end{array}$ & Neonatal pig & - & Safe for animals & [72] \\
\hline Pomegranate seed oil & Rats & - & Improved insulin secretion & [48] \\
\hline
\end{tabular}

de Melo et al. [15] elucidated that oral administration of PA to rats for a time period of 24 hours conferred the metabolism of PA to 9c, 11t-conjugated linoleic acid (CLA) in plasma and other organs of the rats like kidney, liver, brain, heart and adipose tissues. 9c, 11t-CLA plays biologically significant role in maintaining the human body and is considered as an important natural resource of CLA via breakdown of CLnA. In a human trial conducted for 28 days, ingestion of Trichosanthes kirilowii (TK) seed kernels comprising $3 \mathrm{~g}$ PA/day followed by 7 days feeding on sunflower seed kernels eventually increased the level of PA (c9t11c13) in membranes of plasma and red blood cells i.e. $0.47 \%$ and $0.37 \%$ correspondingly.

\section{Cis Trans Cis}

$\mathrm{CH}_{3}\left(\mathrm{CH}_{2}\right)_{3} \mathrm{CH}=\mathrm{CHCH}=\mathrm{CHCH}=\mathrm{CH}\left(\mathrm{CH}_{2}\right)_{7} \mathrm{COOH}$

$9 c, 11 t, 13 c-18: 3$ Octadecatrienoic acid (Punicic acid)

Saturase

Trans Cis

$\mathrm{CH}_{3}\left(\mathrm{CH}_{2}\right)_{5} \mathrm{CH}=\mathrm{CHCH}=\mathrm{CH}\left(\mathrm{CH}_{2}\right)_{7} \mathrm{COOH}$

$9 c, 11 t-18: 2$ Octadecadienoic acid

(Conjugated linoleic acid)

Fig. 1 Metabolism of punicic acid 
Similarly, concentration of 9c, 11t-CLA elevated from 0.05 to $0.23 \%$ and 0.03 to $0.17 \%$ in plasma and red blood cell membranes, respectively.

It was investigated in different studies that uptake rate of CLnA vary in Caco-2 cells when distribution and conversion of CLnA (punicic, $\alpha$ - and $\beta$-eleostearic, and catalpic acid) to CLA is premeditated. Variation in the conversion efficiency is due to the difference in the structure of $\Delta 13$ double bond of CLnA. The CLnA distribute between neutral and phospholipids and this distribution depends upon the number of trans double bonds [24]. Nevertheless, another theory also exists about the conversion of CLnA to CLA. Accordingly, another theory explicates the metabolic conversion of CLnA to CLA is due to $\Delta 13$ double bond saturation reactions catalyzed by an enzyme i.e. nicotinamide adenine dinucleotide phosphate (NADP) that is known as a unique enzyme for conjugated trienoic acid reorganization [25].

In another study, an equi-molar mixture of conjugated linoleic acid (CLnA) (C18:3-9c, 11t, 15c and C18:3-9c, $13 t, 15 c)$ and rumenic acid (RA 18:2-9c, 11t) was orally directed to Wister rats as free fatty acids (FFA) and triacylglycerol (TAG). Both isomers (RA and CLnA) were bio transformed completely in tissues in a similar fashion [26]. Mice supplemented with 1\% PA for six weeks have higher concentration of $\omega-3$ in liver phospholipids than the mice supplemented with $1 \%$ alpha-eleostearic acid [27]. Another experiment revealed similar results when diet was supplemented with 0.5\% PA (PSO) [28]. When absorption and metabolic pathways of PA and alpha-eleostearic acid ( $\alpha$-ESA) was observed via a lipid absorption assay in rat intestine lymph, it was found that some amount of these isomers was converted to CLA rapidly and some remained intact in the intestines [29]. Comparatively, PA accumulates in higher amounts in tissues as compared to $\alpha$-ESA and the conversion rate of $\alpha$-ESA to $9 c, 11 t$-CLA is also higher than PA in liver [27]. The maximum conversion rate of PA was $76 \%$ and $54.5 \%$ while highest conversion rate for $\alpha$-ESA was 91.8\% for adipose tissues, $91.4 \%$ for spleen, $90.7 \%$ for kidney and $84.6 \%$ for heart [27].

\section{Anti-oxidant potential of PA}

Considering the side effects associated with usage of synthetic anti-oxidants and increase in oxidative stress disorders, use of anti-oxidants from natural sources are gaining importance [30]. Numerous studies revealed that PA is biologically active in hampering the hazards associated with oxidative mechanisms $[14,31]$. To evaluate the anti-oxidative potential of PA against lipid peroxidation, various concentrations of PA (snake gourd seed oil) were supplemented to rats through diet after blending it with soybean. A momentous decrease was observed in body weight gain, energy consumption, triglyceride (TG), total cholesterol (TC) and TC/HDL ratio in high fat induced mouse model for five (05) weeks when administered by pomegranate leaf extract [32]. PA showed pro-oxidative (1.2\%), anti-oxidative $(0.6 \%)$ activity and significantly decreased the TC, low density lipoprotein cholesterol (LDL-C) when incorporated as compared to control diet [33]. PA and alpha-tocopherol $(\alpha-\mathrm{AT})$ were tested for its effects against lipid peroxidation in alloxan-induced diabetes mellitus rats. Significant lowering trend was observed in LDL and erythrocyte lipid peroxidation with highest reduction was noticed in liver \& membrane peroxidation due to combined effect of $0.25 \% \mathrm{PA}+0.15 \%$ AT [34]

Activities of anti-oxidative enzymes in liver homogenates, brain, plasma and erythrocytes were altered by inducing sodium arsenite $[35,36]$. Owing to supplementation of CLnA isomers, the activity of catalase (CAT), super-oxidase dismutase (SOD) and glutathione peroxidase $(\mathrm{GPx})$ were increased while decreasing trend was observed in nitric oxide (NO) synthase. However, $\alpha$-ESA was found more effective in decreasing oxidative stress as compared to CLnA. When these isomers were studied against streptozotocin-induced diabetes in albino rats, same results were observed as in above mentioned studies against oxidative stress induced by sodium arsenite [37]. More distinct synergistic effect was observed when both of these isomers were applied in combination [38].

CLnA isomers improved the renal oxidative stress release and showed attired synergistic effects [4, 39]. The supplementation of mixture having both isomers of CLnA helped to improve the fatty acid profile of renal system. A decrease was observed in oxidation with the supplementation of TK seed (3 $\mathrm{g}$ PA). The increased level of 8 -iso-PGF2 $\alpha$ was due to non-enzymatic peroxidation of arachidonic acid [40, 41].

\section{Anti-diabetic properties}

Up till now, experimental studies conducted to test the effect of PA on serum lipid, glucose metabolism and insulin resistance have provided controversial results. Non-significant results were recorded for both body and tissue weight when diet containing 1\% $\alpha$-ESA and/or PA was administered for six weeks [42]. Similar results were obtained when the mice were fed for three weeks on diet containing $0.12 \%$ and $1.2 \%$ PSO [43]. Feeding rats on $1 \%$ PSO and $9 \%$ safflower oil diet for the period of two weeks gives non-significant results for abdominal white adipose tissue weights [44]. In another study, a diet constituted with $\alpha$-ESA and PA was given to hamsters for 6 weeks and reduction in the liver tissue TG levels was observed but no significant results were found for serum TC [45]. However in some other experimental studies, 
the results were in contrast with the above findings [34, 46, 47]. Some scientists found significant effect of $\mathrm{PA}$ on the reduction of $\mathrm{TC}$, apoB-100 and liver tissue TG levels.

Rats that were fed on PSO showed higher levels of insulin in serum and glutathione peroxidase (GOP) activity with no significant difference in blood glucose level as compared to control group [48]. Peony seed oil rich in PA showed reduction in glycosylated total serum cholesterol (TC), triglyceride (TG), glycosylated hemoglobin (HbA1C) level while an increase was observed in weight gain, high density lipoprotein cholesterol (HDL-C), serum insulin level, liver glycogen level in mice [49]. In another study, PSO was fed to rats for 21 days that increased total triacylglycerol (TAG) and phospholipid level in serum while no significant increase was observed in TC level [50]. As the level of PSO increases in diet, the level of PA also increases in epididymal, serum, liver and peri-renal adipose. When mice were supplemented with dietary genetically modified rapeseed oil (GMRO) at $0.25 \%$ weight of the whole diet, it not only lowered the body lipid ratio but also enhanced the liver lipid metabolism as compared to the same quantity of PA taken directly from pomegranate. PSO was consistent in substantially reducing the liver TG levels but no major effects were observed for serum TG, TC, LDL-C and HDL-C levels [13].

When PSO was administered to dyslipidemic patients for four weeks, serum concentration of TNF- $\alpha$ decreased from 15 to $13.08 \mathrm{pg} / \mathrm{ml}$ in the PSO group [51]. Similar scenario transpired when PSO given to high fat induced patients for four (04) weeks. No change occurred in serum TC, LDL-C, glucose concentrations and body composition variables [52]. It was found that supplementation of PSO for 1 month in hyper-lipidaemic subjects had promising effects on lipid profiles including TAG and TAG: HDL-C ratio. In contrast, fasting serum glucose and insulin levels and sensitivity showed no momentous variation due to the Trichosanthes kirilowii Maxim. Diet supplementation analyzed by homeostasis model assessment-insulin resistance (HOMA-IR) [53].

However when PA was given to rats with diet-induced obesity, an improvement was observed in plasma glucose and insulin levels and glucose-normalizing capacity over a glucose tolerance test [38]. An improvement in insulin sensitivity in CD-1 mice was observed with PSO consumption (av. $61 \mathrm{mg} /$ day), signifying that the threat of emerging diabetes type-II might be lessened [54]. Additionally, it was noticed that PSO consumption improves glucose and insulin sensitivity and fat diet-induced obesity in mice. When PA (1\% PSO) was supplemented for the period of three months, ingestion of PA resulted in lipid lowering sequenced by reduction in body weight which ultimately reduced total body mass [17]. PA also improved the peripheral insulin sensitivity without effecting liver insulin sensitivity. So, supplementation of PA through dietary sources is helpful with reference to insulin resistance and fat induced obesity in mice, independent of changes in food intake or energy expenditure.

Xanthigen (a bioactive compound derived from pomegranate) is the precursor of PA and is well known for its lipid lowering potential in animals and humans although its mechanism of action is not yet completely known. Xanthigen potently and dose-dependently suppressed accumulation of lipid droplets in adipocytes compared to its individual components; fucoxanthin and PSO [55]. Various mechanisms are involved in overwhelming the triacylglycerides accretion and adipocyte differentiation by Xanthigen and can be used as potential remedy for the treatment of diabetic patients. Mixture of PA, xanthigen and fucoxanthin acid $(70 \%$ in PSO) was fed to mice to investigate the inhibitory effect on the differentiation of 3T3-L1 pre-adipocytes. A decreased gene expression was observed which was regulating the distinction process that raises TG buildup in 3T3-L1 pre-adipocytes treated with punicic acid [56].

\section{Effect of punicic acid on molecular events}

The most common physiological disorders all around the world like rheumatoid arthritis, inflammatory bowel disease, metabolic syndrome and atherosclerosis that are specified by the occurrence of extremely stimulated inflammatory cells like macrophages, neutrophils, monocytes and overproduction of pro-inflammatory mediators and reactive oxygen species (ROS). These diseases can be effectively controlled by some natural dietary supplements. PA (PSO) is effective against ROS/MPO-mediated tissue damage and reduces the neutrophil-activation [57]. PA has persuasive anti-inflammatory effect and can prove as a natural therapeutic agent (as therapeutic substitute) against various inflammatory diseases [14].

Molecular evidence with reference to in vivo tryouts showed that the uptake of PA regulates colonic PPAR- $\delta$ expression, the keratinocyte growth factor, the orphan nuclear receptor ROR $\gamma$ expression, suppresses colonic and M1 macrophage-derived TNF- $\alpha$. PA also increased the levels of IL-17 and IFN- $\gamma$ in CD8+T cells in the mesenteric lymph nodes (i.e., mucosal inductive sites). PA modulates mucosal immune responses and improves gut inflammation through PPAR- $\gamma$ and $-\delta$-dependent mechanisms $[28,58]$. Likewise, dietary PA lowers fasting plasma glucose concentrations and improves the glucosenormalizing ability eventually suppressing NF- $\mathrm{kB}$ activation and TNF- $\alpha$ expression. Ultimately it regulates PPAR $\alpha$ - and $\gamma$-responsive genes in skeletal muscle and adipose tissue [17]. Experiments have also demonstrated that PA can bind and robustly activate PPAR $-\gamma$ and increase 
PPAR- $\gamma$-responsive gene expression, finally improving diabetic and inflammatory status. Insulin resistance by TNF- $\alpha$ is associated with mitochondrial dysfunction in 3T3-L1 adipocytes and is ameliorated by PA, a PPARY agonist [59].

In an in vitro study, meant at assessing the efficiency and activeness of certain CLnA isomers found in PSO as selective estrogen receptor modulators (SERMs), PA also inhibited estrogen receptors (ER) $\alpha$ and $\beta$ at 7.2 and 8.8 $\mu \mathrm{M}$, respectively; $\alpha$-ESA inhibited ER $\alpha$ and $\beta$ at 6.5 and $7.8 \mu \mathrm{M}$, respectively $[28,60]$. Thus, both CLnA isomers are effective as SERMs. These outcomes specify that PA, rich in PSO and an effective SERM, might be used as a possible breast cancer chemo-preventive agent.

Saha and Ghosh [40] revealed that the diet supplementation with CLnAs ( $\alpha$-ESA and PA at $0.5 \%$ total lipids) showed significant reduction of inflammation in diabetic albino rats induced by streptozotocin. They further elaborated that the above mentioned four weeks diet supplementation led to reduce inflammation by reducing the expression of inflammatory cytokines, such as TNF- $\alpha$ and IL- 6 , in blood and the expression of hepatic NF- $\mathrm{KB}$ (p65), once higher as a result of diabetes induction. Then again, one study also stated that the 400 $\mathrm{mg}$ of pomegranate seed oil (rich in PA) administrated twice daily in dyslipidemic patients had no effect on serum TNF- $\alpha[28,51]$. These findings divulge that the CLnAs in PSO and some other foods may be a promising therapeutic substitute approach for cancer and inflammatory diseases. The further studies should be carried out to attest these effects in humans $[37,57]$.

Neurodegenerative disorders that occur due to the accretion of some special mis-folded proteins like in Alzheimer's diseases occupy almost same pathological features of oxidative damage and neuronal death. PA plays a vital role in controlling these diseases [61]. To examine the effect of PSO for oxidative damage reduction, PSO was encapsulated in a nano-droplet form and was given to TgMHu2ME199K mice (used as a model subject for genetic prion disease). PSO as a high source of rare polyunsaturated fatty acid (PA) is now being considered as a sturdiest biological antioxidant. When nano-PSO was administrated to already sick mice, it not only overdue the disease appearance but the disease aggravation was also delayed. Brain analysis of these mice showed that PSO lessened the fat oxidation and neuronal damage although it did not reduce PrPSc accretion. So, it is clear that PSO is a strong neuro-protective agent and is not only effective against the vulnerable subjects but also for those already experiencing neurodegenerative disorders. In the field of pharma, this kind of formulations can be helpful in ameliorating neurodegenerative disorders [62]. Certainly, nano-PSO is considered as a safe reagent and can be utilized as safe food supplement in different therapies.

Osteoporosis occurrence is increasing day by day and gaining importance as a great threat to long and healthy life expectancy. For the preclusion of osteoporosis, several strategies were developed. PSO is highly effective against inflammatory and oxidative processes as these processes are involved in osteoporosis. A study conducted on ovariectomized (OVX) mice model, supplemented with 5\% PSO diet showed that PSO fed mice have significantly improved bone mineral density with prevention of trabecular micro-architecture impairment by involving osteo-clastogenesis inhibition and osteoblastogenesis improvement. Thus PSO can be suggested as preventive measure against osteoporosis [63].

\section{Food Applications}

Pomegranate seeds considered as the waste product after the processing of fruit into its various products. Pomegranate seed oil and peels were incorporated into icecream to enhance the functional properties and significant changes were observed in product $\mathrm{pH}$, acidity and color while milk fat replacement with PSO improved the fatty acid profile by increasing the conjugated fatty acid contents with elevated antioxidant and anti-diabetic properties due to the phenolic contents [64]. Punicalagins and PA from peel and seed provide the health benefits with improvement in functional properties. Pomegranate seed ethanolic extract (PSEE) possessed the anti-proliferative and antioxidant effects against hormone-dependent prostate carcinoma and human breast cancer cell lines and considered as nutraceutical/functional food ingredient to prevent carcinogenic diseases [65].

Pomegranate seed extract useful in replacing artificial antioxidant in meat products to increase the oxidative stability of such products. Devatkal et al. [66] incorporated the citrus rind powder and pomegranate rind and seed extracts in meat patties. Highest antioxidant effect was observed in pomegranate seed extract. According to such studies, it is believed that industrial by-products of fruits and vegetables are potential source of antioxidant. Pomegranate seed extract helps to reduce the formation of heterocyclic aromatic amines in meat products cooked by various methods with different temperatures and heat [67] thus pomegranate seed useful in producing safe product.

Mohagheghi et al. [68] incorporated PSO (PSO-inwater emulsion) as functional ingredient in juice and beverages with varying concentration of gum Arabic and evaluated the effect on emulsion stability index, droplet size distribution, and turbidity loss rate. The consequences manifested that the beverage emulsions behaved as Newtonian fluids, and this study begins new glimpse to produce relatively stable PSO-in-water emulsions as 
functional ingredient in beverage industry. Encapsulation of PSO and its application in skimmed milk powder as encapsulating agent was studied by [69].

\section{Safety evaluation}

PSO has been consumed for long enough due to its safety as cold pressed oil and is considered an effective measure to reduce the occurrence and incidence of tumor and multiplicity. It is also evident from different ex vivo and in vivo research trials using mice and rats as model subjects. However, there is still very little information is present about the safety and toxic concern of PSO other than the above mentioned evidences. PA is a non-toxic, natural, orally active food ingredient known to humans and consumed by humans for centuries $[70,71]$. Possible mutagenicity of PSO was evaluated by means of in vitro and in vivo toxicity of PSO in Wistar rats [72]. During the presence or absence of metabolic activities, PSO can neither be clastogenic nor mutagenic in nature. No adverse effects of PSO were observed at a dose level of $4.3 \mathrm{~g} / \mathrm{kg}$ body weight/day but at higher concentration $(150,000 \mathrm{ppm})$ of PSO, hepatic enzyme activities are disturbed mainly due to increase in liver weight and liver-to-body ratio.

A short-term safety evaluation of dietary monoconjugated alpha-linolenic acid isomers was executed using a pig model. The outcome of the experiment revealed that intake of mono-CLNA is safe in neonatal pigs for short-term time period. The safety of a mixture of two mono-CLnA c9-t11- c15-18:3 + c9-t13-c15-18:3 isomers was assessed in comparison to other fatty acids having either one conjugated double-bond, an n-3 or n-6 PUFA structures (CLnA vs. CLA; CLnA vs. W3; CLnA vs. W6) and results revealed that a dietary provision of $1 \%$ of these mono-CLnA isomers for 2-weeks can be considered safe for the current animal model [73].

It was observed that during the metabolic activation process, PSO did not show either clastogenicity or mutagenicity up to $33 \mu \mathrm{g} / \mathrm{mL}$ through chromosome aberration test or $5000 \mu \mathrm{g} /$ plate through Ames test [74]. Rats fed on $2 \mathrm{~g}$ PSO/kg body weight did not showed nonsignificant toxicity effect. According to the OECD 423 test guidelines, the LD50 cut-off value supposed to be higher as compared to $5 \mathrm{~g} / \mathrm{kg}$ body weight and PSO could be considered safe food without any labelling or classification requirement. In one 28 days oral toxicity study, PSO was administered to male and female rats at the rate of $150000 \mathrm{ppm}$ with mean intake of $1.39 \mathrm{~g} \mathrm{PSO/}$ $\mathrm{kg}$ body weight/day and it was observed that liver functioning enzymes improved in plasma followed by accretion of liver to body weight ratio. These results could be happened might be due to physiological actions of high dose of PA. According to the above mentioned data, PSO (PA) did not possess any toxic effect at such an elevated level as it's not a part of normal diet at such high level. The no observable adverse effect level (NOAEL) of PA was reported at $50000 \mathrm{ppm}$ as PSO, which is equivalent to $4.3 \mathrm{~g} \mathrm{PSO} / \mathrm{kg}$ body weight/day.

\section{Future concerns}

The emergent data of clinical trials on animals and human models have explored that PA is as an effective bioactive compound that can be operative for human well-being for improved health eminence and chronic diseases preclusion. A minute single dose of PA is sufficient to integrate the physiological health effect within weeks or months with characteristic health changes particularly in clinical trials with compromised health prestige. The outward short-term effect of CLnA isomers supplementation in both liver and brain indicates that long-term toxicology trials in animals should be considered before moving to comprehensive and long-term studies. However, there is no evidence of long term supplementation effects on health related consequences, so it is justified that its effect must be investigated before further supplementation for long term time periods in animal models and before moving to clinical trials on humans. PA may possibly be used as a promising alternative in developing different new strategies for nutritional management and health complications. Further, to explore the potential of PA in improving human health, a continue stream line of research work is needed.

\section{Conclusion}

Pomegranate seed oil (PSO) is abundantly comprised of punicic acid (PA), an isomer of conjugated linolenic acid (CLnA) as confirmed by recent studies around the world. Considering the beneficial aspects of PA in various studies, PSO recommended as a nutraceutical and/ or functional ingredient for food products. However, various studies on the bioactive aspect of PA, there are still some ambiguous and/or antithetical studies also. In some studies, the output of PA showed different results in animal models as compared to the human model. There is demand for the PA studies in human models as these kinds of studies are scarce. In this way, the ultimate mechanism of PA on improving human health can be determined. Furthermore, the impact of the intake of PA (CLnA) as functional food on human body metabolism and other physiological health effects can be understood and finally the safety recommendations for the intake of PA can be developed.

\section{Acknowledgement}

Author(s) wishes to acknowledge the faculty members and supervising instructors for constructive criticism and applause for writing this review article and reviewing it for keeping it at minimal slip-ups in technical aspects with reference to the scientific literature based articles. 


\section{Funding}

Not Applicable.

\section{Availability of data and materials}

The dataset supporting the conclusions of this article is included within the article.

\section{Authors' contributions}

MN conceptualized, provided the technical assistance and guided in the data collection. MI helped for drafting the manuscript. "It's also confirmed that all the authors read and approved the final manuscript".

\section{Competing interests}

The authors declare that they have no competing interests.

\section{Consent for publication}

Not Applicable.

\section{Ethics approval and consent to participate}

Not Applicable.

\section{Publisher's Note}

Springer Nature remains neutral with regard to jurisdictional claims in published maps and institutional affiliations.

\section{Received: 31 March 2017 Accepted: 18 May 2017}

\section{Published online: 30 May 2017}

\section{References}

1. Viuda-Martos M, Ruiz-Navajas Y, Fernández-López J, Pérez-Álvarez JA. Effect of adding citrus waste water, thyme and oregano essential oil on the chemical, physical and sensory characteristics of a bologna sausage. Innovative Food Sci Emerg Technolog. 2009;10:655-60.

2. Johanningsmeier SD, Harris GK. Pomegranate as a functional food and nutraceutical source. Annu Rev Food Sci Technol. 2011:2:181-201.

3. Habibnia M, Ghavami M, Ansaripour M, Vosough S. Chemical evaluation of oils extracted from five different varieties of Iranian pomegranate seeds. J Food Sci Technol. 2012;2:35-40.

4. Ali K, Che-Man YB, Roberts TH. Physico-chemical properties and fatty acid profile of seed oils from pomegranate (Punica granatum L.) extracted by cold pressing. Eur J Lipid Sci Technol. 2014;116:553-62.

5. Guangmin L, Xiang X, Ying G, Li H, Yanxiang G. Effects of supercritical CO2 extraction parameters on chemical composition and free radical-scavenging activity of pomegranate (Punica granatum L.) seed oil. Food Bio-products Processing. 2012;90:573-8.

6. Sargolzaei J, Moghaddam AH. Predicting the yield of pomegranate oil from supercritical extraction using artificial neural networks and an adaptivenetwork-based fuzzy inference system. Front Environ Sci Eng. 2013;7:357-65.

7. Ahangari B, Sargolzaei J. Extraction of pomegranate seed oil using subcritical propane and supercritical carbon dioxide. Theor Found Chem Eng. 2012:46: 258-65.

8. Yuan Y, Li MM, Li CB, Chen Q. Optimization of ultrasound-assisted extraction of pomegranate seed oil using response surface methodology and the composition analysis. Food Sci Technol. 2013;38:179-84.

9. Tian $Y, X u Z$, Zheng B, Martin LY. Optimization of ultrasonic-assisted extraction of pomegranate (Punica granatum L.) seed oil. Ultrason Sonochem. 2013;20:202-8.

10. Abbasi H, Rezaei K, Emamdjomeh Z, Mousavi SME. Effect of various extraction conditions on the phenolic contents of pomegranate seed oil. Eur J Lipid Sci Technol. 2008;110(5):435-40.

11. Lansky EP, Newman RA. Punica granatum (pomegranate) and its potential for prevention and treatment of inflammation and cancer. J Ethnopharmacol. 2007;109:177-206.

12. Kýralan M, Gölükcü M, Tokgöz H. Oil and conjugated linolenic acid contents of seeds from important pomegranate cultivars (Punica granatum L.) grown in Turkey. J Am Oil Chem Soc. 2009;86:985-90.

13. Carvalho Filho JM. Pomegranate seed oil (Punica granatum L.): A source of punicic acid (conjugated a-linolenic acid). J Human Nutri Food Sci. 2014; 2(1):1-11.

14. Aruna $P$, Venkataramanamma D, Singh AK, Singh $R$. Health Benefits of Punicic Acid: A Review. Compr Rev Food Sci Food Saf. 2016;15:16-27.
15. de Melo ILP, de Oliveira e Silva AM, de Carvalho EB, Yoshime LT, JAG S, Mancini-Filho J. Incorporation and effects of punicic acid on muscle and adipose tissues of rats. Lipids Health Dis. 2016;15:1.

16. Hennessy AA, Ross PR, Fitzgerald GF, Stanton C. Sources and Bioactive Properties of Conjugated Dietary Fatty Acids. Lipids. 2016;51:377-97.

17. Vroegrijk IO, van Diepen JA, van den Berg S, Westbroek I, Keizer H, Gambelli L, et al. Pomegranate seed oil, a rich source of punicic acid, prevents diet-induced obesity and insulin resistance in mice. Food Chem Toxicol. 2011;49:1426-30.

18. Abidov M, Ramazanov Z, Seifulla R, Grachev S. The effects of Xanthigen ${ }^{\mathrm{TM}}$ in the weight management of obese premenopausal women with non-alcoholic fatty liver disease and normal liver fat. Diabetes Obes Metab. 2010;12:72-81.

19. Kinami T, Horii N, Narayan B, Arato S, Hosokawa M, Miyashita K, et al. Occurrence of conjugated linolenic acids in purified soybean oil. I Am Oil Chem Soc. 2007;84:23-9.

20. Cao Y, Chen J, Yang L, Chen Z-Y. Differential incorporation of dietary conjugated linolenic and linoleic acids into milk lipids and liver phospholipids in lactating and suckling rats. J Nutr Biochem. 2009;20:685-93.

21. Verardo V, Garcia-Salas P, Baldi E, Segura-Carretero A, Fernandez-Gutierrez A, Caboni MF. Pomegranate seeds as a source of nutraceutical oil naturally rich in bioactive lipids. Food Res Int. 2014:65:445-52.

22. Lucci P, Pacetti D, Loizzo MR, Frega NG. Punica granatum cv. Dente di Cavallo seed ethanolic extract: antioxidant and antiproliferative activities. Food Chem. 2015;167:475-83.

23. $X u$ L, Xu Y, Wang S, Deng Q, Wu C-Y, Chen X-T, Wang H-L. Novel bitter melon extracts highly yielded from supercritical extraction reduce the adiposity through the enhanced lipid metabolism in mice fed a high-fat diet. J Nutri Intermed Metabol. 2016;6:26-32.

24. Wang L, Wang X, Wang P, Xiao Y, Liu Q. Optimization of supercritical carbon dioxide extraction, physicochemical and cytotoxicity properties of Gynostemma pentaphyllum seed oil: A potential source of conjugated linolenic acids. Sep Purif Technol. 2016;159:147-56.

25. Schneider A-C, Mignolet E, Schneider Y-J, Larondelle Y. Uptake of conjugated linolenic acids and conversion to cis-9, trans-11-or trans-9, trans-11-conjugated linoleic acids in Caco-2 cells. Br J Nutr. 2013;109:57-64.

26. Melo ILM. Evaluation of the effects of pomegranate seed oil (Punicagranatum L.) on tissue lipid profile and its influence on biochemical parameters in oxidative processes of rats [thesis]. Sao Paulo (SP): Pharmaceutical Science Faculty of Sao Paulo University; 2012.

27. Stiti N, Chandrasekar B, Strubl L, Mohammed S, Bartels D, van der Hoorn RA Nicotinamide Cofactors Suppress Active-site Labeling of Aldehyde Dehydrogenases. ACS Chem Biol. 2016;11(6):1578-86.

28. Plourde M, Sergiel J-P, Chardigny J-M, Grégoire S, Angers P, Sébédio J-L. Absorption and metabolism of conjugated a-linolenic acid given as free fatty acids or triacylglycerols in rats. Nutr Metab. 2006;3:1.

29. Yuan GF, Sinclair AJ, Sun HY, Li D. Fatty acid composition in tissues of mice fed diets containing conjugated linolenic acid and conjugated linoleic acid. J Food Lipids. 2009;16:148-63.

30. Tsuzuki T, Kawakami Y, Abe R, Nakagawa K, Koba K, Imamura J, et al. Conjugated linolenic acid is slowly absorbed in rat intestine, but quickly converted to conjugated linoleic acid. J Nutr. 2006;136:2153-9.

31. Yuan G, Sun H, Sinclair AJ, Li D. Effects of conjugated linolenic acid and conjugated linoleic acid on lipid metabolism in mice. Eur J Lipid Sc Technol. 2009;111:537-45.

32. Fernandes L, Pereira JA, Lopéz-Cortés I, Salazar DM, Ramalhosa E, Casal S. Fatty acid, vitamin E and sterols composition of seed oils from nine different pomegranate (Punica granatum L.) cultivars grown in Spain. J Food Compos Anal. 2015;39:13-22.

33. Harzallah A, Hammami M, Kępczyńska MA, Hislop DC, Arch JR, Cawthorne MA et al. Comparison of potential preventive effects of pomegranate flower, peel and seed oil on insulin resistance and inflammation in high-fat and high-sucrose diet-induced obesity mice model. Arch Physiol Biochem. 2016;122:75-87.

34. Zarfeshany A, Asgary S, Javanmard SH. Potent health effects of pomegranate. Adv Biomed Res. 2014:3:100.

35. Mukherjee C, Bhattacharyya S, Ghosh S, Bhattacharyya DK. Dietary Effects of Punicic Acid on the Composition and Peroxidation of Rat Plasma Lipid. J Oleo Sci. 2002;51:513-22.

36. Dhar P, Bhattacharyya D, Bhattacharyya D, Ghosh S. Dietary comparison of conjugated linolenic acid (9 cis, 11 trans, 13 trans) and a-tocopherol effects on blood lipids and lipid peroxidation in alloxan-induced diabetes mellitus in rats. Lipids. 2006;41:49-54. 
37. Saha SS, Ghosh M. Antioxidant effect of vegetable oils containing conjugated linolenic acid isomers against induced tissue lipid peroxidation and inflammation in rat model. Chem Biol Interact. 2011;190:109-20.

38. Tandon N, Roy M, Roy S, Gupta N. Protective effect of Psidium guajava in arsenic-induced oxidative stress and cytological damage in rats. Toxicol Int. 2012;19:245.

39. Mabrouk A, Cheikh HB. Thymoquinone ameliorates lead-induced suppression of the antioxidant system in rat kidneys. Libyan J Med. 2016;11(1):1-5.

40. Saha SS, Ghosh M. Antioxidant and anti-inflammatory effect of conjugated linolenic acid isomers against streptozotocin-induced diabetes. Br J Nutr. 2012;108:974-83.

41. Saha SS, Dasgupta P, Sengupta S, Ghosh M. Synergistic effect of conjugated linolenic acid isomers against induced oxidative stress, inflammation and erythrocyte membrane disintegrity in rat model. Biochim Biophys Acta Gen Subj. 2012;1820:1951-70.

42. Saha SS, Ghosh M. Protective effect of conjugated linolenic acid isomers present in vegetable oils against arsenite-induced renal toxicity in rat model. Nutrition. 2013:29:903-10.

43. Yoshida Y, Umeno A, Akazawa Y, Shichiri M, Murotomi K, Horie M. Chemistry of lipid peroxidation products and their use as biomarkers in early detection of diseases. J Oleo Sci. 2015;64:347-56.

44. Tassone EJ, Perticone M, Sciacqua A, Mafrici SF, Settino C, Malara N, et al. Low dose of acetylsalicylic acid and oxidative stress-mediated endothelial dysfunction in diabetes: a short-term evaluation. Acta Diabetol. 2015;52: 249-56.

45. Boroushaki MT, Mollazadeh H, Afshari AR. Pomegranate seed oil: A comprehensive review on its therapeutic effects. Int J Pharm Sci Res. 2016;7:430.

46. Liu WN, Leung KN. The Immunomodulatory Activity of Jacaric Acid, a Conjugated Linolenic Acid Isomer, on Murine Peritoneal Macrophages. Plos One. 2015;10:e0143684.

47. Arao K, Wang Y-M, Inoue N, Hirata J, Cha J-Y, Nagao K, et al. Dietary effect of pomegranate seed oil rich in 9cis, 11 trans, 13cis conjugated linolenic acid on lipid metabolism in obese, hyperlipidemic OLETF rats. Lipids Health Dis. 2004;3:1.

48. Yang L, Leung KY, Cao Y, Huang Y, Ratnayake W. Chen Z-Y: a-Linolenic acid but not conjugated linolenic acid is hypocholesterolaemic in hamsters. Br J Nutr. 2005;93:433-8

49. Koba K, Imamura J, Akashoshi A, Kohno-Murase J, Nishizono S, Iwabuchi M, et al. Genetically modified rapeseed oil containing cis-9, trans-11, cis-13octadecatrienoic acid affects body fat mass and lipid metabolism in mice. J Agric Food Chem. 2007;55:3741-8.

50. Arao K, Yotsumoto H, Han S-Y, Nagao K, Yanagita T. The 9 cis, 11 trans, 13 cis isomer of conjugated linolenic acid reduces apolipoprotein B100 secretion and triacylglycerol synthesis in HepG2 cells. Biosci Biotechnol Biochem. 2004:68:2643-5.

51. Nekooeian AA, Eftekhari MH, Adibi S, Rajaeifard A. Effects of pomegranate seed oil on insulin release in rats with type 2 diabetes. Iran J Med Sci. 2014;39:130-5

52. Su J, Wang H, Ma C, Lou Z, Liu C, Rahman MT, et al. Anti-diabetic activity of peony seed oil, a new resource food in STZ-induced diabetic mice. Food Funct. 2015;6:2930-8.

53. Yamasaki M, Kitagawa T, Koyanagi N, Chujo H, Maeda H, Kohno-Murase J, et al. Dietary effect of pomegranate seed oil on immune function and lipid metabolism in mice. Nutrition. 2006;22:54-9.

54. Yuan GF, Sinclair AJ, Sun HY, Li D. Fatty acid composition in tissues of mice fed diets containing conjugated linolenic acid and conjugated linoleic acid. J Food Lipids. 2009;16(2):148-63.

55. Asghari G, Sheikholeslami S, Mirmiran P, Chary A, Hedayati M, Shafiee $A$, et al. Effect of pomegranate seed oil on serum TNF-a level in dyslipidemic patients. Int. J Food Sci Nutr. 2012;63:368-71.

56. Mirmiran P, Fazeli MR, Asghari G, Shafiee A, Azizi F. Effect of pomegranate seed oil on hyperlipidaemic subjects: a double-blind placebo-controlled clinical trial. Br J Nutr. 2010;104:402-6.

57. Yuan G-F, Yuan J-Q, Li D. Punicic acid from Trichosanthes kirilowii seed oil is rapidly metabolized to conjugated linoleic acid in rats. J Med Food. 2009;12: 416-22.

58. McFarlin BK, Strohacker KA, Kueht ML. Pomegranate seed oil consumption during a period of high-fat feeding reduces weight gain and reduces type 2 diabetes risk in CD-1 mice. Br J Nutr. 2009;102:54-9.
59. Lange KW, Hauser J, Nakamura Y, Kanaya S. Dietary seaweeds and obesity. Food Sci Human Wellness. 2015:4:87-96.

60. Lai C-S, Tsai M-L, Badmaev V, Jimenez M, Ho C-T, Pan M-H. Xanthigen suppresses preadipocyte differentiation and adipogenesis through downregulation of PPARY and C/EBPS and modulation of SIRT-1, AMPK, and FoxO pathways. J Agric Food Chem. 2012;60:1094-101.

61. Boussetta T, Raad H, Lettéron P, Gougerot-Pocidalo M-A, Marie J-C, Driss F, et al. Punicic acid a conjugated linolenic acid inhibits TNFa-induced neutrophil hyperactivation and protects from experimental colon inflammation in rats. PloS One. 2009;4:e6458.

62. Bassaganya-Riera J, Diguardo M, Climent M, Vives C, de Horna A, Sanchez S, et al. Punicic acid modulates mucosal immune responses and prevents gut inflammation through PPAR gamma- and delta-dependent mechanisms. FASEB J. 2010;24:926.926.

63. Rodriguez J, Gilson H, Jamart C, Naslain D, Pierre N, Deldicque $L$, et al. Pomegranate and green tea extracts protect against ER stress induced by a high-fat diet in skeletal muscle of mice. Eur J Nutr. 2015;54:377-89.

64. Cam M, Erdogan F, Aslan D, Dinc M. Enrichment of functional properties of ice cream with pomegranate by-products. J Food Sci. 2013;78:1543-50.

65. Mudie K, Gebregzabher A, Kassa D. investigation of the biochemical mechanism of action of antioxidants in the prevention of cancer. Int J Pharm Sci Res. 2015:6:4556.

66. Devatkal SK, Narsaiah K, Borah A. Anti-oxidant effect of extracts of kinnow rind, pomegranate rind and seed powders in cooked goat meat patties. Meat Sci. 2010;85:155-9.

67. Keskekoglu H, Uren A. Inhibitory effects of pomegranate seed extract on the formation of heterocyclic aromatic amines in beef and chicken meatballs after cooking by four different methods. Meat Sci. 2014;96:1446-51.

68. Mohagheghi M, Rezaei K, Labbafi M, Mousavi M. Pomegranate seed oil as a functional ingredient in beverages. Eur J Lipid Sci Technol. 2011;113:730-6.

69. Goula AM, Adamopoulos KG. A method for pomegranate seed application in food industries: Seed oil encapsulation. Food Bioprod Process. 2012;90: 639-52.

70. Anusree S, Nisha V, Priyanka A, Raghu K. Insulin resistance by TNF-a is associated with mitochondrial dysfunction in 3T3-L1 adipocytes and is ameliorated by punicic acid, a PPARy agonist. Mol Cell Endocrinol. 2015:413:120-8.

71. Tran HNA, Bae S-Y, Song B-H, Lee B-H, Bae Y-S, Kim Y-H, et al. Pomegranate (Punica granatum) seed linolenic acid isomers: concentration-dependent modulation of estrogen receptor activity. Endocr Res. 2010;35:1-16.

72. Thakur A, Mandal SC, Banerjee S. Compounds of Natural Origin and Acupuncture for the Treatment of Diseases Caused by Estrogen Deficiency. J Acupunct Meridian Stud. 2016;9(3):109-17.

73. Mizrahi M, Friedman-Levi Y, Larush L, Frid K, Binyamin O, Dori D, et al. Pomegranate seed oil nanoemulsions for the prevention and treatment of neurodegenerative diseases: the case of genetic CJD. Nanomed: Nanotechnol, Biol Med. 2014;10:1353-63.

74. Spilmont M, Léotoing L, Davicco M-J, Lebecque P, Mercier S, Miot-Noirault $E$, et al. Pomegranate seed oil prevents bone loss in a mice model of osteoporosis, through osteoblastic stimulation, osteoclastic inhibition and decreased inflammatory status. J Nutr Biochem. 2013;24:1840-8.

75. Bassaganya-Riera J. Method of using punicic acid to enhance immune response and prevent metabolic disorders. Google Patents. 2014;8,822,543.

76. Wang L, Li W, Lin M, Garcia M, Mulholland D, Lilly M, Martins-Green M. Luteolin, ellagic acid and punicic acid are natural products that inhibit prostate cancer metastasis. Carcinogenesis. 2014;35(10):2321-30.

77. Meerts I, Verspeek-Rip C, Buskens C, Keizer H, Bassaganya-Riera J, Jouni Z, et al. Toxicological evaluation of pomegranate seed oil. Food Chem Toxicol. 2009:47:1085-92.

78. Castellano C-A, Plourde M, Briand SI, Angers P, Giguère A, Matte JJ. Safety of dietary conjugated a-linolenic acid (CLNA) in a neonatal pig model. Food Chem Toxicol. 2014;64:119-25. 